\title{
ВЭЖХ определение малонового диальдегида в плазме и слюне с очисткой дериватов на сверхсшитом полистироле (Purosep-270)
}

\author{
Дутов А.А. ${ }^{1}$, Никитин Д.А. ${ }^{2}$, Ермолина А.В. ${ }^{1}$, Лукьянова Ю.Л. ${ }^{1}$, \\ Мищенко М.Н. ${ }^{1}$, Шемякина Н.А. ${ }^{1}$, Рудакова Л.В. ${ }^{3}$ \\ ${ }^{1}$ ФББОУ ВО «Читинская государственная медииинская академия», Чита \\ ${ }^{2}$ ФГБОУ ВО «Воронежский государственный университет», Воронеж \\ ${ }^{3}$ ФГБОУ ВО «Воронежский государственный медицинский университет», Воронеж
}

Поступила в редакцию 1.12.2017 г.

Для целей клинических исследований предложен хроматографический способ определения общего малонового диальдегида (МДА) в плазме и слюне после дериватизации с 2-тиобарбитуровой кислотой (ТВА). Полученные дериваты очищали на картриджах со сверхсшитым полистиролом марки Purosep-270. Разделение на C18 колонках, детекция при 530 нм. Полное хроматографическое разделение за 4 минуты. Стандартизованы и оптимизированы условия приготовления и хранения стандартов, дериватизационного реагента и биологического материала. Предел количественного обнаружения (LOQ) составил 0.05 нг на инъекцию при соотношении сигнал/шум=10. Метод отличается простотой, хорошей воспроизводимостью при соблюдении всех условий и может быть рекомендован для рутинных клинических анализов МДА в плазме и слюне.

Ключевые слова: ВЭЖХ, малоновый диальдегид, 2-тиобарбитуровая кислота, сверхсшитый полистирол, плазма, слюна.

\section{HPLC analysis of malonic dialdehyde in plasma and saliva with the purification of derivatives on super-cross-linked polystyrene (Puroxep-270)}

\author{
Dutov A.A.1, Nikitin D.A. ${ }^{2}$, Ermolina A.V. ${ }^{1}$, Lukyanova Yu.L. ${ }^{1}$, \\ Mishchenko M.N. ${ }^{1}$, Shemyakina N.A. ${ }^{1}$, Rudakova L.V. ${ }^{3}$ \\ ${ }^{1}$ Chita State Medical Academy, Chita \\ ${ }^{2}$ Voronezh State University, Voronezh \\ ${ }^{3}$ Voronezh State Medical University, Voronezh
}

Malondialdehyde (MDA) is a marker of oxidative stress, but its determination in biological fluids is quite a challenge. In its native form, malonic dialdehyde practically does not determine. The main problem is the choice of the method of hydrolysis of plasma and the method of deproteinization, which significantly affects the yield of malonic dialdehyde. The aim of this work was to develop a simple and reproducible way to determine free MDA in blood plasma and saliva.

The investigations were carried out by HPLC: a high pressure pump (Shimadzu LC-20AT Prominence), a spectrophotometric detector (Shimadzu SPD-20A Prominence), a manual injector (Rheodyne 7725i), a chromatographic column Luna $150 \times 4.6 \mathrm{~mm}, \mathrm{C} 18$ (2), $5 \mu \mathrm{m}$ (Phenomenex, USA) with an efficiency of about 8500 TT. For protection, a 0.2 micron pre-column filter (Supelco, USA) was used. Data processing was carried out using software («Multichrome» version 3.0, Ampersand). 
As a derivatization reagent, a solution of 2-thiobarbituric acid was proposed. The optimal way of deproteinization was chosen. A technology of solid-phase extraction / purification of derivatives has also been developed. This procedure allows not only to clean, but concentrate the extract, which increases the sensitivity of the determination. Cartridges with super-cross-linked polystyrene Purosep-270 were used for solid-phase extraction.

The obtained chromatographic results showed that the yield of MDA after the step of solid-phase purification was $80-84 \%(n=33)$. The use of the solid-phase purification procedure made it possible to compensate for the dilution effect of the extracts of the bioassay resulting from the sample preparation, thereby increasing the sensitivity of the assay. As a result, there is no need for fluorometric detection and, as it follows from chromatograms, detection in the visible range at $530 \mathrm{~nm}$ is possible. The limit of quantitative detection (LOQ) was $0.05 \mathrm{ng}$ per injection at a signal-to-noise ratio of 10.

The results of the analysis can be used for diagnosis since the concentration of MDA in saliva can be affected not only by systemic but local diseases of the oral cavity. For this aim it is necessary to accumulate a database and take into account the current conditions (storage of biomaterial, conditions for preparation of the standard and derivatization reagent, conditions for derivatization and solid-phase cleaning)

Thus, the developed sorption-chromatographic method for determining total malonic dialdehyde in blood plasma and saliva after derivatization with 2-thiobarbituric acid and solid phase purification / concentration (if it is necessary) is simple, well reproducible and can be recommended for routine clinical analyzes.

Keywords: HPLC, malondialdehyde, 2--thiobarbituric acid, hyper cross-linked polystyrene, plasma, saliva.

\section{Введение}

Определение малонового диальдегида в биологических жидкостях как маркера оксидативного стресса имеет клиническуюй значимость $[1,2]$. Некоторые исследователи считают, что более надежным маркером является 4-гидроксиноненаль [3]. Определение МДА и других низкомолекулярных карбонилов считается трудной аналитической задачей [4], решению которой посвящен целый ряд работ. Основные проблемы касаются выбора метода гидролиза плазмы: комбинированный (сначала щелочной, затем кислотный $[5 ; 6 ; 7])$ или только кислотный $[2,8]$. Важное значение имеет выбор последующего метода депротеинизации, оказывающего существенное влияние на выход МДА [9]. В нативном виде МДА практически не определяют, очевидно, в силу его высокой полярности, хотя он имеет достаточно хорошее поглощение при 245 или 267 нм [10, 11]. Производные или дериваты МДА получают путем реакции с различными веществами: тиобарбитуровой кислотой $[2,6,12,13], 2,4-$ динитро-фенилгидразином [7, 11, 14, 15], дансилгидразином (dansyl hydrazine) [16], 2,2'-фурилом (2,2'-Furil) [17] и fmoc-гидразином (fmoc-hydrazine) [8]. Эти производные поглощают в ультрафиолетовом и видимом диапазонах спектра, а некоторые обладают флюресценцией, что делает возможным их анализ с помощью УФ или флюориметрического детектора. Использование различных способов пробоподготовки, включая варьируемую температуру гидролиза и дериватизации, а также особенности приготовления и хранения стандарта, привело к тому, что определяемая и приводимая различными авторами концентрация общего МДА в плазме имеет большой разброс значений: от 0.11 [12] до 13.8 мкмоль/дм ${ }^{3}$ [18]. В настоящей работе предлагается простой и воспроизводимый способ определения свободного МДА в плазме крови путем реакции с 2-тиобарбитуровой кислотой и возможностью последующей очистки дериватов на картриджах со сверхсшитым полистиролом марки $\mathrm{Pu}-$ rosep-270.

\section{Эксперимент}

Стандарты и реактивы. В работе применяли следующие реактивы: ацетонитрил «о.с.ч. сорт 1» (Криохром), метанол, изопропанол и хлороформ «х.ч.» (Вектон), 
трифторуксусная кислота (TFA) (>99\%, Химмед), водный аммиак «о.с.ч.» (НеваРеактив), серная кислота «х.ч.» (Мосреактив), 2-тиобарбитуровая кислота (ТВА) (>98\%, Sigma-Aldrich), 1,1,3,3-тетраэтоксипропан (TEP) (>98\%, Sigma-Aldrich). Фосфатный буферный раствор $0.5 \mathrm{M} \mathrm{c} \mathrm{pH} 7.0$ готовили смешиванием $\mathrm{Na}_{2} \mathrm{HPO}_{4}$ и $\mathrm{NaH}_{2} \mathrm{PO}_{4}$ (>98\%, Fluka) в соответствующих пропорциях [6]. Для приготовления элюента его разбавляли водой до $0.025 \mathrm{M}$.

Оборудование. Исследования проводили с использованием высокоэффективного жидкостного хроматографа, в комплектацию которого входят: насос высокого давления («Shimadzu» LC-20AT Prominence), спектрофотометрический детектор («Shimadzu» SPD-20A Prominence), ручной инжектор («Rheodyne» 7725i). Хроматографическая колонка Luna 150×4.6 мм, C18(2), 5 мкм (Phenomenex, USA) с эффективностью около 8500 TT. Для защиты использовали 0.2 мкм предколоночный фильтр (Supelco, USA). Обработку данных проводили с применением программного обеспечения («Мультихром» версия 3.0, Амперсанд).

Для перемешивания использовали Intelli-Mixer RM-1L (Elmi, Латвия) и ультразвуковую ванну (Branson-1510, USA), дериватизацию проводили в сушильном электрошкафу с пассивной конвекцией СНОЛ-3.5 («Рембыттермо», Новосибирск).

Биологические образцы. Кровь отбирали в вакутайнеры с ЭДТА, центрифугировали 5 мин при $3000 \mathrm{rpm}$ (CM-6M, Elmi, Латвия). Плазму отбирали и до анализа помещали в холодильник при $4^{\circ} \mathrm{C}$, где ее хранили не более 1 часа. Хранение при комнатной температуре более 3 часов приводит к завышенным в 1.5-2 раза значениям МДА. Если анализ не проводился в тот же день, плазму замораживали и хранили при $-20^{\circ} \mathrm{C}$.

Получение стандарта. В колбу с крышкой наливали 100 мл дистиллированной воды, добавляли 25 мкл 1,1,3,3-тетраэтоксипропана (ТЕР) и перемешивали в ультразвуковой ванне в течение 10 мин. Полученный раствор сохраняется не более 1 часа, при выдерживании его при комнатной температуре более 3 часов, получаются резко завышенные значения дериватов после обработки 2-тиобарбитуровой кислотой (ТВА). Возможно, причиной нестабильности ТЕР является его склонность к реакции самоконденсации [5]. Отбирали $1 \mathrm{~cm}^{3}$ свежего раствора ТЕР, добавляли $9 \mathrm{~cm}^{3}$ воды, $0.1 \mathrm{~cm}^{3}$ концентрированной серной кислоты и выдерживали 1 час в термостате при $40^{\circ} \mathrm{C}$. Схема кислотного гидролиза ТЕР приведена на рис. 1, аналогичная схема применима для другого часто используемого стандарта MDA - тетраметоксипропана.

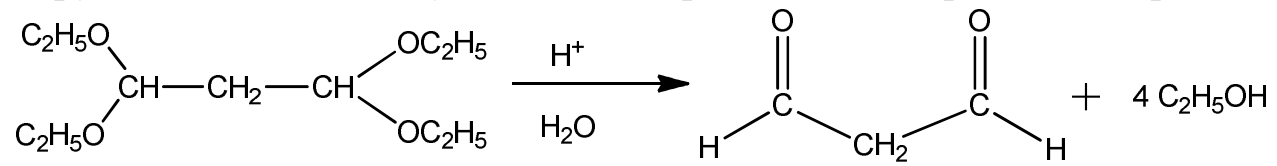

Рис.1. Превращение тетраэтоксипропана в малоновый диальдегид при кислотном гидролизе [10, 12].

После охлаждения полученный раствор (25 нг/мкл) хроматографировали (рис. 2) и в дальнейшем использовали для дериватизации. Раствор сохраняется при $4^{\circ} \mathrm{C}$ как минимум 3 дня.

Дериватизационный реагент готовили растворением 2-тиобарбитуровой кислоты в воде $\left(4 \mathrm{mг} / \mathrm{cm}^{3}\right)$. Перемешивали на вортексе переворачиванием в течение 10 15 мин до полного растворения. Подогревать для улучшения растворимости нежелательно, поскольку возможно взаимодействие с альдегидами и кетонами воздуха (сопровождается появлением розоватой окраски), такой реагент использовать не следует. Использовали только свежеприготовленный раствор. 

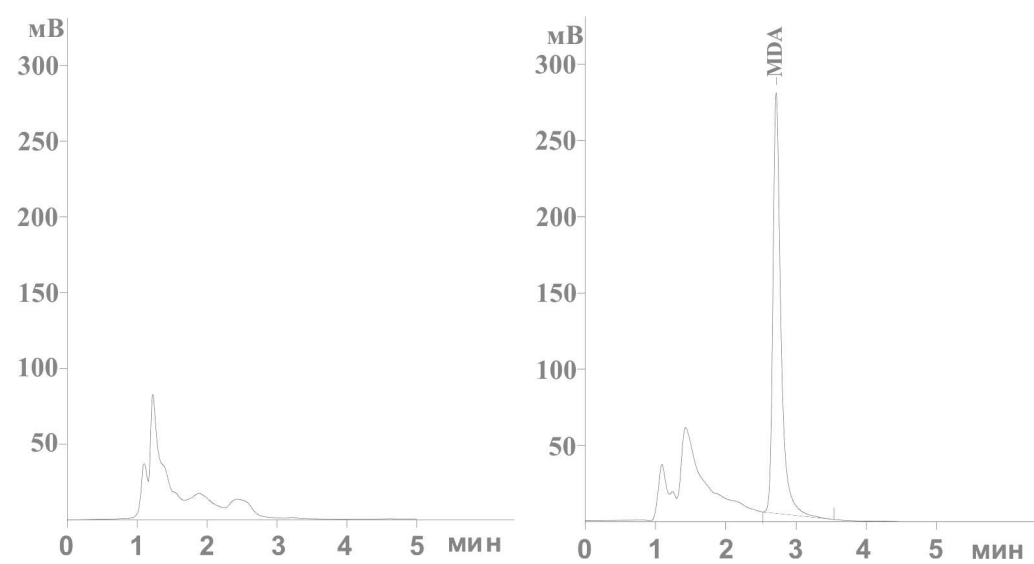

Рис. 2. Хроматограммы растворителя для MDA (слева, 4 мкл 1\% H2SO4) и стандарта нативного MDA (справа, 4 мкл, 100 нг). Колонка Luna 100×4.6 мм, C18(2), 5 мкм, детекция при 245 нм, элюент 5\% водный ацетонитрил, скорость потока 1000 мкл/мин, давление 63 бара.

Дериватизация стандарта. В $1.5-\mathrm{cm}^{3}$ пробирку Эппендорфа добавляли 50 мкл

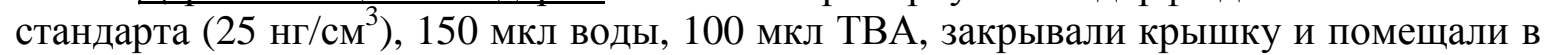
термостат на 30 мин при $85^{\circ} \mathrm{C}$ одновременно с биопробами. Перед дериватизацией стандартов добавлять TFA не обязательно, поскольку дериватизационная реакция стандарта от $\mathrm{pH}$ не зависит [5]. После окончания реакции дериват приобретает розовую окраску. К нему добавляли 700 мкл воды и 4 или 8 мкл (5 и 10 нг соответственно) вводили в петлю дозатора. К другой порции стандарта добавляли 100 мкл воды и подвергали SPE-очистке (описание ниже).

Дериватизация биологического материала. В $1.5-\mathrm{cm}^{3}$ пробирку Эппендорфа добавляли 200 мкл плазмы или слюны, 5 мкл TFА и 100 мкл ТВА, закрывали крышку и помещали в термостат. В отличие от стандартов значение $\mathrm{pH}$ в этом случае имеет большое значение. Кислая среда препятствует взаимодействию ТВА с другими компонентами биоматрикса, сходными с МДА [5]. Сравнительная дериватизация с разными кислотами $\left(\mathrm{HClO}_{4}, \mathrm{H}_{2} \mathrm{SO}_{4}, \mathrm{HCl}, \mathrm{H}_{3} \mathrm{PO}_{4}, \mathrm{HCOOH}, \mathrm{CH}_{3} \mathrm{COOH}, \mathrm{CF}_{3} \mathrm{COOH}\right.$; по 5 мкл каждой) показала, что лучшие результаты получаются при использовании трифторуксусной кислоты. Рекомендации некоторых авторов использовать фосфорную кислоту [2, 5] не вполне оправдано. В наших экспериментах использование фосфорной кислоты в разных концентрациях (от 0.1 до 1\%) приводило к нестабильным результатам при обработке стандартов и биологических проб. Схема дериватизационной реакции приведена на рис. 3 .<smiles>CC(CC=O)CC1CC(=O)NC(=S)N1</smiles>

Рис. 3. Реакция малонового диальдегида с 2-тиобарбитуровой кислотой.

В результате реакции образуются производные розового цвета (стандарт) или практически бесцветные (биопробы). Нагревание проводили в кислой среде в течение 30-45 мин при температуре $90-100^{\circ} \mathrm{C}[2,5,6,12,13]$. По окончании реакции вводили в петлю инжектора 30 мкл (соответствует $0.02 \mathrm{~cm}^{3}$ биологического материала) или предварительно производили дополнительную твердофазную очистку.

Депротеинизация. Для определения МДА в плазме используют разные методы депротеинизации. При определении общего МДА сначала проводят щелочной 
гидролиз, затем депротеинизируют хлорной кислотой и дериватизируют с TBA [5, 15]. Некоторые исследователи считают, что для анализа общего МДА не обязательно проводить щелочной гидролиз, достаточно провести кислотный (10 мкл $\mathrm{H}_{2} \mathrm{SO}_{4}$ на $1 \mathrm{~cm}^{3}$ плазмы) и выдержать 1 час при комнатной температуре [8], или с $0.1 \% \mathrm{H}_{3} \mathrm{PO}_{4}$ в течение 30 мин при $90^{\circ} \mathrm{C}$ [2]. А для свободного МДА достаточно осадить протеины ацетонитрилом (1 часть на 1 часть плазмы) [8]. Экспериментальная проверка предлагаемых методик показала, что они дают недостаточно воспроизводимые результаты. Депротеинизация с помощью хлорной кислоты с последующей дериватизацией ТВА по данным авторов [9] имеет выход МДА менее 40\%. В силу этих обстоятельств для анализа свободного МДА нами был применен другой способ депротеинизации, который был разработан ранее для определения $\beta$-лактамных антибиотиков [19]. К $0.5 \mathrm{~cm}^{3}$ плазмы или слюны, добавляли $0.5 \mathrm{~cm}^{3}$ ацетонитрила, интенсивно перемешивали и центрифугировали 2 мин при 10000 обр/мин. Отбирали $0.8 \mathrm{~cm}^{3}$ супернатанта, добавляли $3 \mathrm{~cm}^{3}$ хлороформа и перемешивали переворачиванием в течение 5 мин. Центрифугировали 3 мин при 2000 обр/мин и 200 мкл верхнего водного слоя использовали для дериватизации по описанной выше схеме. В петлю инжектора вводили 30 мкл (соответствует $0.02 \mathrm{~cm}^{3}$ биологической жидкости).

Ряд исследователей указывают на неспецифичность (недостаточную селективность) ТВА как дериватизационного реагента, поскольку ТВА вступает в реакцию с рибозой, глицеролом, биливердином, аминопиримидинами и сиаловой кислотой, которые присутствуют в биологическом материале [20, 21]. Поэтому, несмотря на проведенную нами работу по устранению дестабилизирующих факторов анализа, в качестве дополнительного варианта была разработана технология SPE-очистки дериватов. К тому же такая очистка позволяет сконцентрировать экстракт, что повышает чувствительность определения.

Твердофазная экстракция/очистка (SPE). Использовали картриджи на основе 1-см ${ }^{3}$ полипропиленовых шприцов (Supelco), упакованные 5 мг сверхсшитого полистирола (Purosep-270) по собственной технологии [22]. Картридж кондиционировали, пропуская последовательно по $0.5 \mathrm{~cm}^{3}$ хлороформа, метанола и воды.

Твердофазная экстракция стандартов: к $0.3 \mathrm{~cm}^{3}$ дериватов стандартов добавляли $0.1 \mathrm{~cm}^{3}$ воды, 5 мкл ТFА и вводили в картридж дважды по $0.2 \mathrm{~cm}^{3}$. Промывали дважды по $0.2 \mathrm{~cm}^{3}$ воды, подсушивали под вакуумом 10-15 сек и элюировали дериваты $0.2 \mathrm{~cm}^{3}$ смеси ацетонитрил-метанол- $\mathrm{NH}_{4} \mathrm{OH}$ (объемные соотношения 1:1:0.02) в пробирку Эппендорфа. Добавляли $0.8 \mathrm{~cm}^{3}$ воды, 5 мкл ТFА (для нейтрализации аммиака) и 4 или 8 мкл вводили в петлю инжектора (соответственно 5 или 10 нг).

Твердофазная экстракциия биопроб: К $0.3 \mathrm{~cm}^{3}$ добавляли $0.1 \mathrm{~cm}^{3}$ воды и вводили в картридж. TFA не добавляли, поскольку она уже была добавлена перед дериватизацией. Промывка и элюирование проводились также, как и для стандартов. В петлю вводили 20 или 40 мкл (соответствует 0.02 или $0.04 \mathrm{~cm}^{3}$ плазмы или слюны).

В процессе разработки были оптимизированы условия загрузки и элюирования на стандартах. Промывку оставили только водой с учетом высокой полярности дериватов. При кислой (с TFA) и нейтральной (с фосфатным буферным раствором $\mathrm{pH}$ 7.0) загрузке и элюировании $0.2 \mathrm{~cm}^{3}$ метанола, выход дериватов МДА составил 59 и $61 \%$ соответственно. Таким образом, можно сделать вывод, что рН загрузки не влияет на экстракцию. Поскольку метанол не полностью смывает дериваты с сорбента, на следующем этапе оценили эффективность различных элюирующих смесей (табл. 1). Наибольший выход (98\% деривата МДА) обеспечивала элюирующая смесь состава ацетонитрил - метанол - $\mathrm{NH}_{4} \mathrm{OH}$ (в объемном соотношении 1:1:0.02). 
Таблица 1. Результаты использования элюирующих смесей для деривата МДА

\begin{tabular}{|c|c|}
\hline Элюирующая смесь (по $\left.0.2 \mathrm{~cm}^{3}\right)$ & Выход деривата МДА, \% \\
\hline Ацетонитрил - метанол $(1: 1, \mathrm{v} / \mathrm{v})$ & 72 \\
\hline Ацетонитрил - метанол - ДМСО $(1: 1: 0.1, \mathrm{v} / \mathrm{v} / \mathrm{v})$ & 82 \\
\hline Ацетонитрил - метанол - $\mathrm{NH}_{4} \mathrm{OH}(1: 1: 0.02, \mathrm{v} / \mathrm{v} / \mathrm{v})$ & 98 \\
\hline * Выход дериватов $(n=5$ с каждой смесью) оценивали по площади пиков. ДМСО - диметилсульфок-
\end{tabular}
сид.

Таким образом, SPE-очистка позволила получить дополнительно очищенные дериваты без разбавления: первоначальный объем биопробы $0.2 \mathrm{~cm}^{3}$, финальный объем элюата также $0.2 \mathrm{~cm}^{3}$. Концентрирование возможно только в варианте увеличения объема биопробы до 0.4-0.6 см³. Упаривание элюата недопустимо, поскольку даже в щадящем режиме при 50-60 $\mathrm{C}$, получаются сильно завышенные значения МДА и, кроме того, за счет этого значительно удлиняется процедура.

По окончании работы промывали картриджи $0.5 \mathrm{~cm}^{3} 0.1 \mathrm{M} \mathrm{NaOH}, 0.5 \mathrm{~cm}^{3}$ воды, $0.5 \mathrm{~cm}^{3}$ ацетонитрила, заполняли $1 \mathrm{~cm}^{3}$ изопропанола и хранили в таком виде до следующего анализа. При соблюдении этих условий, картриджи выдерживают несколько сотен экстракций без потери эффективности.

\section{Обсуждение результатов}

На рис. 4 приведены результаты хроматографирования экстракта плазмы. Полученные результаты показали, что выход МДА-ТВА после этапа твердофазной очистки составил 80-84\% ( $n=33)$. Использование процедуры твердофазной очистки позволило компенсировать обусловленный пробоподготовкой эффект разбавления экстрактов биопроб и тем самым повысить чувствительность анализа. В результате отпала необходимость во флюориметрическом детектировании и, как следует из представленных хроматограмм, вполне достаточно детекции в видимом диапазоне при $530 \mathrm{HM}$.

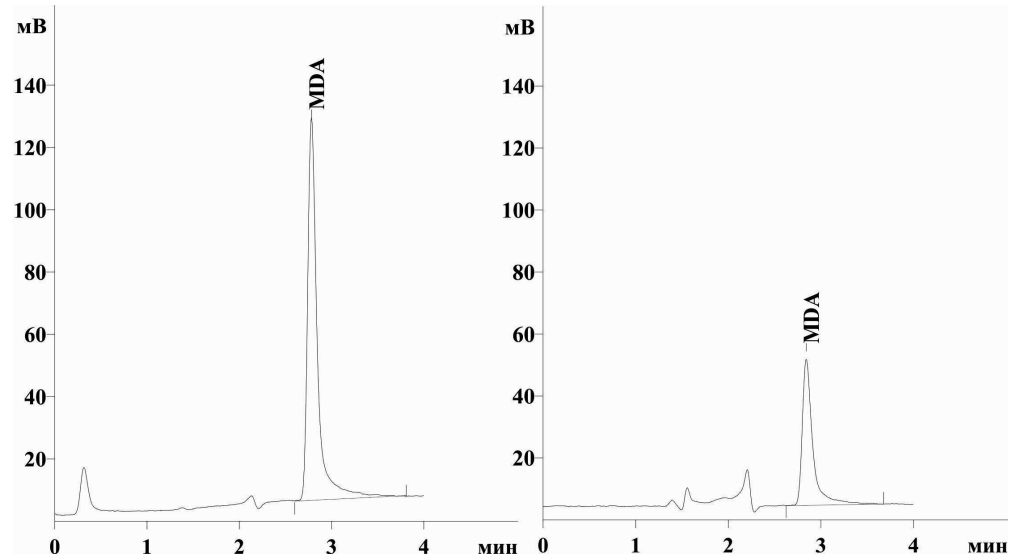

Рис. 4. Хроматограммы стандарта 5 нг (4 мкл) (слева) и экстракта плазмы 30 мкл $\left(0.02 \mathrm{~cm}^{3}\right)$ (справа) после дериватизации с ТВА. Концентрация МДА 58 нг/см ${ }^{3}$ или 0.81 мкмоль/дм ${ }^{3}$. Колонка Luna 150×4.6 мм, C18(2), 5 мкм, детекция при 530 нм, элюент 22\% ацетонитрила и $78 \% 0.025 \mathrm{M}$ фосфатного буферного раствора с $\mathrm{pH} 7.0$, скорость потока 1000 мкл/мин, давление 76 бар.

Предел количественного обнаружения (LOQ) составил 0.05 нг на инъекцию при соотношении сигнал/шум=10. Литературные данные и результаты собственных наблюдений, проведенных с помощью разработанного метода, представлены в таблице 2. 
Таблица 2. Концентрация МДА в плазме после дериватизации с ТВА

\begin{tabular}{|c|c|c|}
\hline \multicolumn{2}{|c|}{ МДА, $\mu \mathrm{mol} / \mathrm{L}$} & \multirow{2}{*}{ Авторы } \\
\hline Мужчины & Женщины & \\
\hline $0.41-1.29(n=107)$ & $0.33-1.22(n=106)$ & Nielsen et al, 1997 \\
\hline $4.60 \pm 0.95(n=20)$ & $4.45 \pm 0.81(n=45)$ & Grotto et al, 2007 \\
\hline \multicolumn{2}{|c|}{$2.2 \pm 1.4(n=38)$} & Domijan et al, 2015 \\
\hline \multicolumn{2}{|c|}{$0.454 \pm 0.066(n=15)$} & Carbonneau et al, 1991 \\
\hline \multicolumn{2}{|c|}{$5.78-13.79(n=4)$} & Moselhy et al, 2013 \\
\hline \multicolumn{2}{|c|}{$0.11 \pm 0.06(n=40)$} & Templar et al, 1999 \\
\hline \multicolumn{2}{|c|}{$1.19 \pm 0.59(n=15)$} & Наши данные \\
\hline
\end{tabular}

Разброс значений, полученных разными авторами, обусловлен тем, что существенное влияние на выход МДА из биологического материала оказывают температура гидролиза и дериватизации. При высокой температуре возможен de novo синтез МДА [2]. Для минимизации влияния температурного фактора были проведены эксперименты, в которых дериватизацию проводили при комнатной температуре для последующего анализа методом газовой хроматографии - масс-спектрометрии (GC-

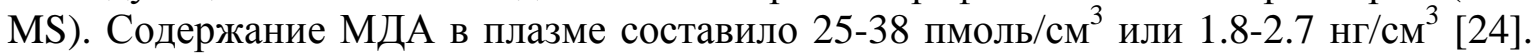
Имеющееся у других авторов более чем 10-кратное превышение концентрации МДА в плазме обусловлено жесткими температурными условиями дериватизации. О таком же 10-кратном превышении сообщали другие авторы [11] и потому дериватизацию проводили не с ТВА, а с 2,4-динитрофенилгидразином, который быстро и эффективно взаимодействует с МДА при комнатной температуре. В наших исследованиях дериватизацию проводили при $85^{\circ} \mathrm{C}$, поскольку при комнатной температуре реакция с ТВА практически не идет.

Мы не видим особой проблемы в de novo синтезе МДА, поскольку этот эффект характеризует способность тканей к синтезу МДА, которая, вероятно, различна у здоровых и больных людей. Однако, с учетом этого факта, при массовых рутинных анализах, правильным будет создание собственной базы значений нормы содержания МДА в биологических жидкостях для реализуемых условий анализа (хранение биоматериала, условия приготовления стандарта и дериватизационного реагента, условия дериватизации и SPE-очистки). В слюне содержание МДА у тех же людей $(n=15$, средний возраст 46 лет) в несколько раз ниже, чем в плазме (таблица 3$)$.

Таблица 3. Концентрация общего МДА в слюне после дериватизации с ТВА

\begin{tabular}{|c|c|}
\hline МДА, $\mu \mathrm{mol} / \mathrm{L}$ & Авторы \\
\hline $0.26 \pm 0.05(\mathrm{n}=30)$ & Smriti et al, 2016 \\
\hline $0.15 \pm 0.11(\mathrm{n}=30)$ & Shirzad et al, 2014 \\
\hline $0.065 \pm 0.05(\mathrm{n}=30)$ & Guentsch et al, 2008 \\
\hline $0.23 \pm 0.11(\mathrm{n}=15)$ & Наши данные \\
\hline
\end{tabular}

Надо отметить, что на концентрацию МДА в слюне могут оказывать влияние не только системные, но локальные заболевания полости рта, и результаты анализа, при накоплении базы данных, можно использовать для диагностики и мониторинга эффективности лечения стоматологических заболеваний.

\section{Заключение}

Таким образом, разработанный сорбционно-хроматографический способ определения общего малонового диальдегида в плазме крови и слюне после деривати- 
зации с 2-тиобарбитуровой кислотой и твердофазной очистки/концентрирования (при необходимости) отличается простотой, хорошей воспроизводимостью и может быть рекомендован для рутинных клинических анализов.

$$
\begin{gathered}
\text { Авторы благодарят проф. Даванкова Вадима Александровича } \\
\text { за предоставленный сорбент }
\end{gathered}
$$

\section{Список литературы}

1. Del Rio D, Stewart AJ, Pellegrini N. // Nutrition, Metabolism \& Cardiovascular Diseases. 2005. Vol. 15, pp. 316-328. doi:10.1016/j.numecd.2005.05.003.

2. Domijan AM, Ralić J, Radić Brkanac S, Rumora L. et al. // Biomed Chromatogr. 2015. Vol. 29(1), pp. 41-46. DOI: 10.1002 / bmc.3361

3. Novo Erica and Parola Maurizio // Fibrogenesis \& Tissue Repair. 2008. Vol. 1(5), pp. 158.

4. Shibamoto T. // Journal of Pharmaceutical and Biomedical Analysis. 2006. Vol. 41. pp. 1225. DOI:10.1016/j.jpba.2006.01.047

5. Carbonneau MA, Peuchant E, Sess D, Canioni P and Clerc M. // Clin Chem. 1991. Vol. 37/8. pp. 1423-1429.

6. Grotto D, Santa Maria LD, Boeira S, Valentini J. et al. // Journal of Pharmaceutical and Biomedical Analysis. 2007. Vol. 43. pp. 619624. DOI:10.1016 / j.jpba.2006.07.030

7. Mateos R, Lecumberri E, Ramos S, Goya L, Bravo L. // J. Chromatogr. B Analyt. Technol. Biomed. Life Sci. 2005. Vol. 827. pp. 76-82. DOi:10.1016/j.jchromb.2005.06.035

8. Mao J, Zhang H, Luo J, Li L, Zhao R. // J. Chromatogr. B Analyt. Technol. Biomed. Life Sci. 2006. Vol. 832, pp. 103-108. DOI:10.1016/ j.jchromb.2005.12.041

8. Lepage G, Munoz Gl, Champagne J and Roy CC. // Anal. Biochem. 1991. Vol. 197. pp. 277-283.

9. Marnett LJ, Bienkowski MJ, Raban M., Tuttle MA. // Analytical Biochemistry. 1979. Vol. 99. pp. 458-463.

10. Korchazhkina O, Exley C, Spencer SA. // Journal of Chromatography B. 2003. Vol. 794. pp. 353-362. DOI:10.1016 / S15700232(03)00495-1

11. Templar J, Kon SP, Milligan TP, Newman DJ, Raftery MJ. // Nephrol Dial Transplant. 1999. Vol. 14. pp. 946-951.

12. Moselhy HF, Reid RG, Yousef S, Boyle SP. // Journal of Lipid Research. 2013. Vol. 54. pp. 852-858. DOI 10.1194 / jlr.D032698
12. Cordis GA, Das DK, Riedel W. // J Chromatogr A. 1998. Vol. 798(1-2). pp. 117-123.

13. Pilz J, Meineke I, Gleiter CH. // J Chromatogr B Biomed Sci Appl. 2000. Vol. 742(2). pp. 315-325.

14. Lord HL, Rosenfeld J, Volovich V, Kumbhare D. et al.// Journal of Chromatography B. 2009. Vol. 877. pp. 1292-1298. DOI:10.1016/j.jchromb.2008.12.035

15. El-Maghrabey MH, Kishikawa N, Ohyama K, Kuroda N. // Anal Biochem. 2014. Vol. 464. pp. 36-42.

16. Sim AS, Salonikas C, Naidoo D, Wilcken DE. // J Chromatogr B Analyt Technol Biomed Life Sci. 2003. Vol. 785. pp. 337-344.

17. Рудаков О.Б., Селеменев В.Ф., Рудакова Л.В. ВЭЖХ. Сорбаты, сорбенты и элюенты. Воронеж. ВГАСУ. 2016. 205 с.

18. Jehl F, Gallion $\mathrm{C}$ and Monteil H. // J. Chromatogr. - Biomed. Appl. 1990. Vol. 96. pp. 509-548.

19. Gutteridge JMC, Tickner TR. // Anal Biochem. 1978. Vol. 91(1). pp. 250-257.

20. Janero DR. // Free Radic Biol Med. 1990. Vol. 9(6). pp. 515-540.

21. Guentsch A, Preshaw PM, Bremer-Streck S, Klinger G., et al. // Clin Oral Investig. 2008. Vol. 12(4). pp. 345-52.

22. Дутов А.А. Биомедицинская хроматография. М. ГЭОТАР-медиа. 2016. 312 с.

23. Yeo HC, Helbock HJ, Chyu DW, Ames BN. // Analytical Biochemistry. 1994. Vol. 220. pp. 391-396.

24. Shirzad A, Pouramir M, Seyedmajidi M, Jenabian N. et al. // J Dent Res Dent Clin Dent Prospects. 2014. Vol. 8(1), pp. 35-39.

25. Smriti K, Pai KM, Ravindranath V, Pentapati KC. // J Oral Biol Craniofac Res. 2016. Vol. 6(1). pp. 41-44. 


\section{References}

1. Del Rio D, Stewart AJ, Pellegrini N., Nutrition, Metabolism \& Cardiovascular Diseases, 2005, Vol. 15, pp. 316-328. DOI: 10.1016 / j.numecd.2005.05.003.

2. Domijan AM, Ralić J, Radić Brkanac S, Rumora L, Žanić-Grubišić T., Biomed Chromatogr., 2015, Vol. 29(1), pp. 41-46. DOI: 10.1002 / bmc. 3361 .

3. Novo Erica and Parola Maurizio. Fibrogenesis \& Tissue Repair, 2008, Vol. 1(5), pp. 158.

4. Shibamoto T. Journal of Pharmaceutical and Biomedical Analysis, 2006, Vol. 41, pp. 1225. DOI:10.1016 / j.jpba.2006.01.047.

5. Carbonneau MA, Peuchant E, Sess D, Canioni P . et al., Clin Chem, 1991, Vol. 37/8, pp. 1423-1429.

6. Grotto D, Santa Maria LD, Boeira S, Valentini J. et al., , Journal of Pharmaceutical and Biomedical Analysis, 2007, Vol. 43, pp. 619624. DOI:10.1016 / j.jpba.2006.07.030

7. Mateos R, Lecumberri E, Ramos S, Goya L, Bravo L. , J. Chromatogr. B Analyt. Technol. Biomed. Life Sci, 2005, Vol. 827, pp. 76-82. DOi:10.1016/ j.jchromb.2005.06.035

8. Mao J, Zhang H, Luo J, Li L, Zhao R, Zhang R, Liu G. , J. Chromatogr. B Analyt. Technol. Biomed. Life Sci., 2006, Vol. 832, pp. 103-108. DOI:10.1016 / j.jchromb.2005.12.041

8. Lepage G, Munoz Gl, Champagne J and Roy CC. , Anal. Biochem, 1991, Vol. 197, pp. 277-283.

9. Marnett LJ, Bienkowski MJ, Raban M,Tuttle MA., Analytical Biochemistry, 1979, Vol. 99, pp. 458-463.

10. Korchazhkina O, Exley C, Spencer SA. , Journal of Chromatography B, 2003, Vol. 794, pp. 353-362. DOI:10.1016 / S15700232(03)00495-1

11. Templar J, Kon SP, Milligan TP, Newman DJ, Raftery MJ., Nephrol Dial Transplant, 1999, Vol. 14, pp. 946-951.

Дутов Алексей Александрович - д.м.н., проф. кафедры химии Забайкальского Государственного Университета, Чита

Никитин Денис Александрович - аспирант кафедры аналитической химии Воронежского государственного университета, Воронеж
12. Moselhy HF, Reid RG, Yousef S, Boyle SP., Journal of Lipid Research, 2013, Vol. 54, pp. 852-858. DOI 10.1194 / jlr.D032698

12. Cordis GA, Das DK, Riedel W., J Chromatogr A, 1998, Vol. 798(1-2), pp. 117-123.

13. Pilz J, Meineke I, Gleiter CH., J Chromatogr B Biomed Sci Appl, 2000, Vol. 742(2), pp. 315-325.

14. Lord HL, Rosenfeld J, Volovich V, Kumbhare D, Parkinson B., Journal of Chromatography B, 2009, Vol. 877, pp. 1292-1298. DOI:10.1016/ j.jchromb.2008.12.035

15. El-Maghrabey MH, Kishikawa N, Ohyama K, Kuroda N., Anal Biochem, 2014, Vol. 464, pp. 36-42.

16. Sim AS, Salonikas C, Naidoo D, Wilcken DE., J Chromatogr B Analyt Technol Biomed Life Sci, 2003, Vol. 785, pp. 337-344.

17. Rudakov O.B., Selemenev V.F., Rudakova L.V. HPLC. Sorbaty, sorbenty i ehlyuenty. Voronezh, VGASU, 2016, $205 \mathrm{p}$.

18. Jehl F, Gallion $\mathrm{C}$ and Monteil H., $J$. Chromatogr. - Biomed. Appl, 1990, Vol. 96, pp. 509-548.

19. Gutteridge JMC, Tickner TR., Anal Biochem, 1978, Vol. 91(1), pp. 250-257.

20. Janero DR., Free Radic Biol Med, 1990, Vol. 9(6), pp. 515-540.

21. Guentsch A, Preshaw PM, Bremer-Streck S, Klinger G, Glockmann E, Sigusch BW., Clin Oral Investig, 2008, Vol. 12(4), pp. 345-52.

22. Dutov A.A. Biomedicinskaya hromatografiya. Moskva, GEHOTAR-media, 2016, $312 \mathrm{c}$.

23. Yeo HC, Helbock HJ, Chyu DW and Ames BN., Analytical Biochemistry, 1994, Vol. 220, pp. 391-396.

24. Shirzad A, Pouramir M, Seyedmajidi M, Jenabian N, Bijani A, Motallebnejad M., J Dent Res Dent Clin Dent Prospects, 2014, Vol. 8(1), pp. 35-39.

25. Smriti K, Pai KM, Ravindranath V, Pentapati KC., J Oral Biol Craniofac Res., 2016, Vol. 6(1), pp. 41-44.

Dutov Alexey A. - MD, prof. Department of Chemistry of Transbaikal State University, Chita, e-mail: dutovaa@yandex.ru

Nikitin Denis A. - post graduate student, department of analytical chemistry, chemical faculty, Voronezh State University, Voronezh, e-mail: nikitinnd@gmail.com 
Ермолина Алена Владимировна - врач офтальмолог инновационной клиники «Академия Здоровья», Чита

Лукьянова Юлия Львовна - заведующая отделением неврологии Клинической больницы № 1, Чита

Мищенко Мария Николаевна - к.м.н., врачстоматолог стомат. клиники Медицинской Академии, Чита

Шемякина Надежда Анатольевна ассистент кафедры общей хирургии Читинской медицинской академии, Чита

Рудакова Людмила Васильевна - д.х.н., доцент, заведующий кафедрой фармацевтической химии и фармацевтической технологии Воронежского государственного медицинского университета, Воронеж
Ermolina Alena V. - ophthalmologist of the Innovation Clinic "Academy of Health", Chita

Lukyanova Julia L. - Head of Neurology Department, Clinical Hospital No. 1, Chita

Mishchenko Maria N. - Ph.D, physician, Medical Academy, Chita

Shemyakina Nadezhda A. - assistant, Department of Total Surgery, Medical Academy, Chita

Rudakova Lyudmila V. - doctor of science, head of Department of pharmaceutical chemistry and pharmaceutical technology, pharmaceutical faculty, Voronezh State Medical University, Voronezh, e-mail: vodoley65@mail.ru 